\title{
Pelatihan Lukisan Talenan Kepada Remaja Mantan Napi di Shelter Rumah Hati Jombang
}

\author{
Agnes Peny Puspitoningtyas ${ }^{1 *}$, Hartini ${ }^{2}$, Nur Alinda Wati ${ }^{3}$, Tika Ayu Damayanti ${ }^{4}$ \\ 1,2,3,4 Pendidikan Guru Sekolah Dasar, Universitas PGRI Madiun
}

A R T I C L E I N F O

Article history:

Received 20 February 2019

Received in revised form 10 March 2019

Accepted 30 April 2019

Available online 27 May 2019

Kata Kunci:

Shelter Rumah Hati, lukisan

talenan, pelatihan

Keywords:

Shelter Rumah Hati, cutting

board painting, training

\begin{abstract}
A B S T R A K
Tim pengabdian masyarakat dari Universitas PGRI Madiun telah melakukan pelatihan lukisan talenan kepada remaja mantan napi di Shelter Rumah Hati jombang. Shelter Rumah Hati adalah tempat penampungan bagi remaja yang baru saja keluar dari penjara. Tujuan dari pelatihan ini adalah (1) Untuk memberi pengetahuan tentang cara pembuatan lukisan talenan kepada mantan narapidana di Rumah Hati Jombang, agar mereka bisa membuka lapangan pekerjaan bagi dirinya sendiri ataupun orang lain.(2) Untuk memberikan pendampingan kepada anak-anak dan remaja yang berada di Shelter Rumah Hati Jombang.(3) Untuk memberikan keterampilan yang modern kepada anak-anak dan remaja di Shelter Rumah Hati Jombang. Metode yang dilakukan dalam program ini ada 3 yaitu tahap persiapan, tahap pelaksanaan dan tahap evaluasi. Hasil dari pelatihan ini adalah remaja mantan napi sangat antusias dengan adanya pelatihan ini dan mereka bisa membuat lukisan talenan yang memiliki daya jual yang tinggi.
\end{abstract}

\section{A B S T R A C T}

The community service team from the University of PGRI Madiun has carried out cutting board painting training for teenagers who were former prisoners in Rumah Hati Shelter in Jombang. Rumah Hati Shelter is a shelter for teenagers who have just come out of prison. The objectives of the training are (1) To provide knowledge on how to make cutting board paintings for former inmates at Rumah Hati Jombang, that they open employment opportunities for themselves or others. (2) To provide assistance to children and adolescents who is being in Rumah Hati Jombang Shelter (3) To provide modern skills to children and young people in Rumah Hati Jombang Shelter. There are three methods used in this program, namely the preparation, implementation and evaluation stages. The results of this training were that young former prisoners were very enthusiastic about the training, and they could make cutting board paintings that had high selling power. The community service team from the University of PGRI Madiun has carried out cutting board painting training for teenagers who were former prisoners in Rumah Hati Shelter in Jombang. Rumah Hati Shelter is a shelter for teenagers who have just come out of prison. The objectives of the training are (1) To provide knowledge on how to make cutting board paintings for former inmates at Rumah Hati Jombang, that they open employment opportunities for themselves or others. (2) To provide assistance to children and adolescents who is being in Rumah Hati Jombang Shelter (3) To provide modern skills to children and young people in Rumah Hati Jombang Shelter. There are three methods used in this program, namely the preparation, implementation and evaluation stages. The results of this training were that young former prisoners were very enthusiastic about the training, and they could make cutting board paintings that had high selling power.

\footnotetext{
* Corresponding author.

E-mail addresses: agnespeny12@gmail.com (Agnes Peny Puspitoningtyas)
} 


\section{Pendahuluan}

Pada umumnya masyarakat masih banyak yang mempunyai pandangan negatif terhadap mantan napi. Anak mantan napi oleh masyarakat dianggap sebagai trouble maker atau pembuat kerusuhan yang selalu meresahkan masyarakat sehingga masyarakat melakukan penolakan dan mewaspadainya. Sikap penolakan masyarakat membuat narapidana mengalami kesulitan dalam melakukan resosialisasi di masyarakat. Dan yang terjadi pada saat ini adalah, masih banyak orang-orang di masyarakat yang tidak memperdulikan dan mengucilkan kehadiran mantan narapidana untuk dijadikan bagian dari anggota dalam kehidupan masyarakat.

Kesulitan yang dialami narapidana antara lain untuk mendapatkan kembali kepercayaan dari masyarakat di sekitarnya dan kesulitan dalam memperoleh pekerjaan. Susahnya bagi mantan napi untuk kembali lagi ke masyarakat, atau takut akan diperkucilkan dan dihina oleh orang lain. karena mereka merasa rendah diri, dan tidak memiliki kepercayaan yang tinggi bahwa dia juga manusia yang diciptakan untuk bersosialisai kepada lingkungannya. Dari hal tersebut maka perlu diketahui bagaimana sikap optimisme masa depan narapidana yang masih menjalani masa hukuman dalam menghadapi masa kebebasan atau setelah selesai menjalani hukuman. Karena manusia sebagai makluk sosial, tidak bisa hidup sendiri untuk memenuhi kebutuhan hidupnya. Manusia pasti akan membutuhkan orang lain untuk bisa berkembang dan saling berkebutuhan dan saling mempengaruhi.

Di Perum Mojogapit Indah Jombang terdapat sebuah lembaga sosial yakni Shelter Rumah Hati yang mendampingi dan membina anak- anak dan remaja yang baru keluar dari Lembaga Pemasyarakatan (Lapas), baik dari lapas Kediri, lapas anak Blitar, dan lapas Mojokerto. Lembaga ini menanamkan nilainilai pendidikan Islam kepada mantan narapidana anak, khusunya dalam hal ibadah. Shelter Rumah Hati merupakan suatu lembaga yang memberikan tempat bagi anak untuk tinggal sementara setelah keluar dari Lapas. Selama 3 bulan mereka akan mendapatkan pendampingan psikologis dan memberikan keterampilan agar mereka dapat kembali ke masyarakat. Diharapkan dengan pemberian keterampilan seperti keterampilan reparasi motor, komputer, kerajinan dan pelatihan seni budaya, anak-anak dan remaja yang mampu mandiri baik secara ekonomi maupun secara personal ketika kembali pada masyarakat. Dan kemandirian secara ekonomi akan memberikan perasaan berharga yang akan memperkecil kemungkinan anak mengulangi perbuatannya lagi. Shelter Rumah Hati Jombang hanya memberikan keterampilan yang sudah umum kepada anak-anak dan remaja.

Dizaman globalisasi seperti sekarang ini dan teknologi yang semakin canggih, bisnis kerajian tangan sangat merajalela dikalangan masyarakata awam. Kerajinan tangan juga dapat menghasilkan uang jika memiliki nilai estetika. Seperti halnya sebuah telenan di kehidupan nyata biasanya digunakan untuk memasak sekarang bisa dibuat untuk media lukisan, dan jika lukisan telenan mempunyai nilai estetika juga dapat menghasilkan keuntungan yang tinggi.

Oleh karena itu tim PKM-M dari UNIVERSITAS PGRI MADIUN dalam proses pengabdian kepada masyarakat, mengadakan pelatihan terhadap remaja Di Shelter Rumah Hati, Jombang, Jawa Timur. Untuk melatih membuat telenan lukis kepada remaja yang putus sekolah agar mereka mendapatkan pekerjaan yang layak dan dapat diterima oleh masyarakat.

\section{Metode}

Pelatihan Lukisan Talenan untuk Remaja Mantan Napi di Shelter Rumah Hati yang berlokasi di Perumahan Mojongapit, diadakan selama 4 bulan. Metode yang dilakukan dalam program ini melalui 3 tahap yaitu persiapan, pelaksanaan dan evaluasi. Berikut langkah-langkahnya : 


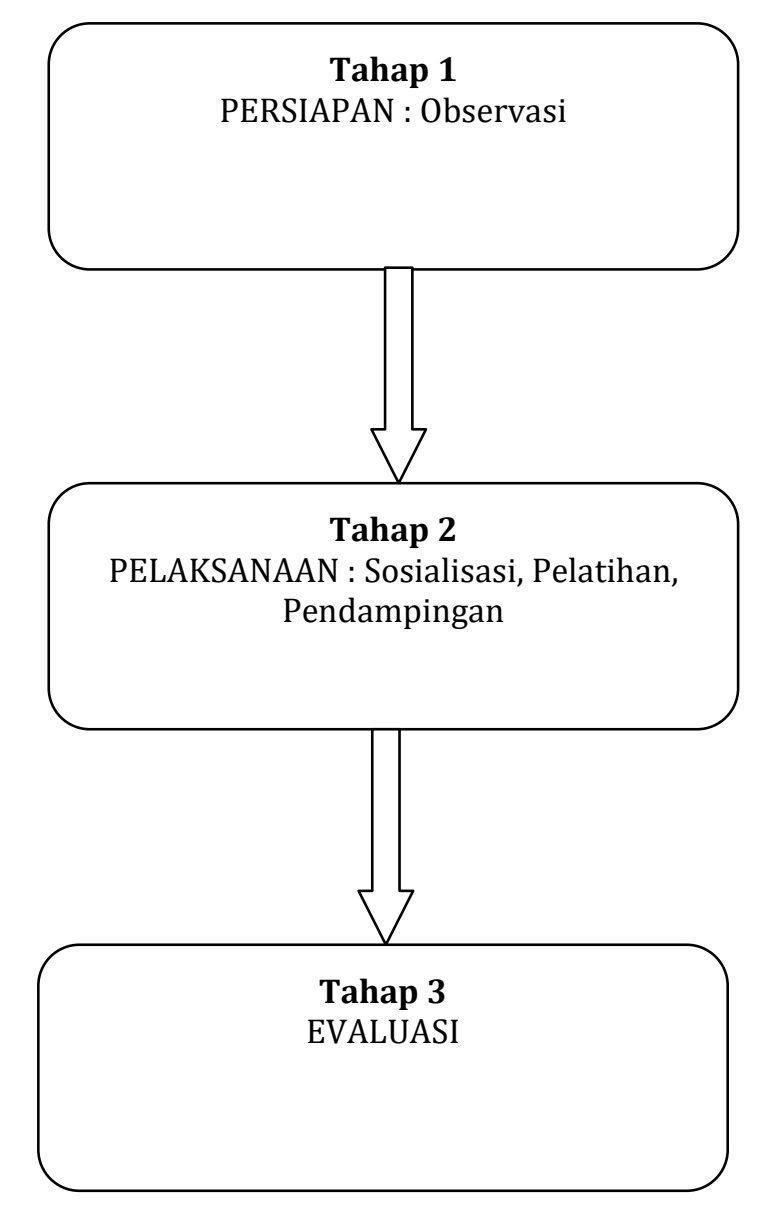

Gambar 1. Diagram metode pelatihan lukisan talenan.

Kegiatan evaluasi yang dilakukan bertujuan untuk mengetahui kemajuan dan efektivitas pelatihan dan bantuan yang diberikan. Evaluasi dilakukan dengan memberikan kuesioner kepuasan serta intrumen Tes untuk mengukur kemampuan penyerapan materi yang terkait dengan lukisan talenan. Hasil dari evaluasi menjadi gambaran, untuk mengembangkan program dan pelatihan lebih lanjut.

\section{Hasil dan pembahasan}

Pelatihan lukisan talenan kepada remaja mantan napi di Shelter Rumah Hati Jombang dilakukan dengan 3 tahap yaitu :

\section{Tahap 1. Persiapan}

Pelaksanaan kegiatan PKM-M dimulai dari observasi ke Shelter Rumah Hati Jombang pada tanggal 28 Maret 2019. Kegiatan observasi dilakukan untuk melihat situasi remaja yang ada di Shelter Rumah Hati Jombang dan minta izin untuk melakukan kegiatan PKM-M di sana dengan judul "Pelatihan lukisan talenan kepada remaja mantan Napi di Shelter Rumah Hati Jombang". 


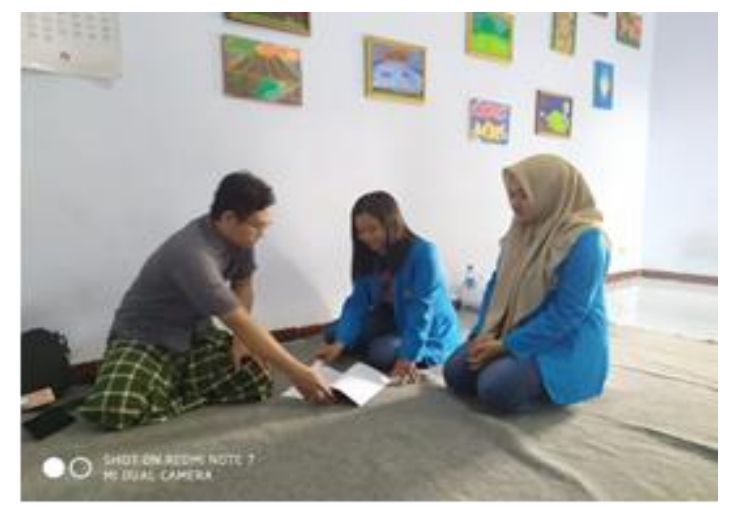

Gambar 2. Observasi

\section{Tahap 2. Pelaksanaan}

1. Tahap Sosialisasi.

Tahap sosialisasi diadakan pada tanggal 11 April 2019, tahap sosialisasi adalah tahap awal dalam tahap pelaksanaan. Kegiatan pertama adalah mensosialisasikan segala sesuatu yang berkaitan dengan lukisan talenan, seperti : apa yang dimaksudkan dengan lukisan talenan, tujuan, manfaat dan bagaimana membuat lukisan talenan, dan menjelaskan maksud dan tujuan kami kepada remaja yang berada di Shelter Rumah Hati Jombang untuk berpartisipasi dalam kegiatan ini. Materi yang disampaikan dijelaskan oleh salah satu tim PKM-M.

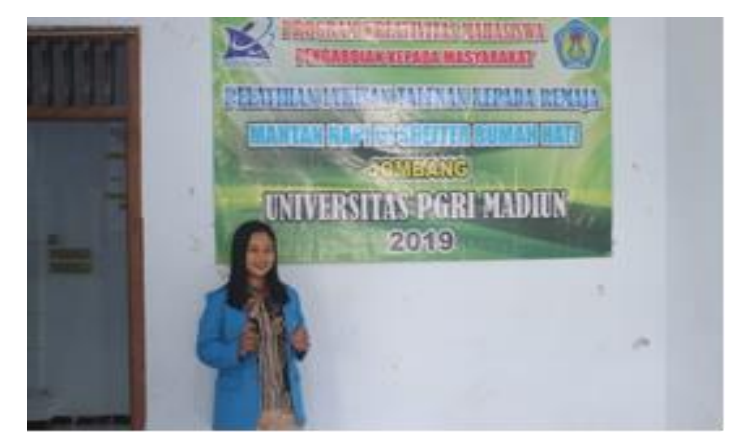

Gambar 3. Sosialisasi

2. Tahap Pelatihan.

Pada tahap pelatihan ini dilakukan pada tanggal 12- 15 April 2019. Pelatihan lukisan talenan ini berada di Shelter Rumah Hati Jombang yang melibatkan remaja mantan napi. Dalam pelatihan ini dihadiri oleh sekitar 10 remaja yang berada di Shelter Rumah Hati Jombang. Tahap awal yang di lakukan yaitu memberikan penjelasan mengenai cara membuat talenan sampai lukisan talenan itu menjadi bagus dan memiliki daya jual yang tinggi.

3. Tahap Pendampingan.

4.
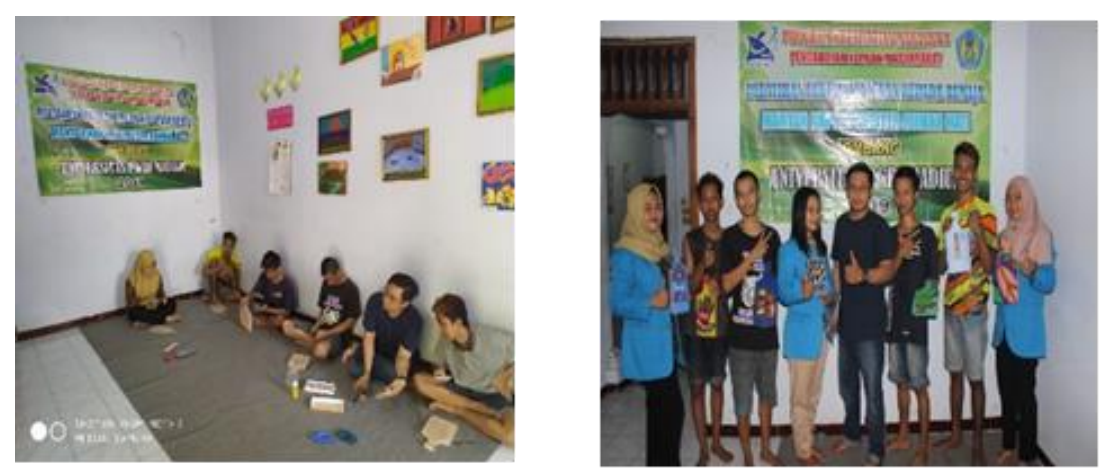

Gambar 4. Pelatihan dan Pendampingan 


\section{Tahap 3. Evaluasi}

Evaluasi terhadap program ini dilakukan setelah semua kegiatan pelatihan selesai, hal ini di maksudkan agar Tim PKM-M UNIPMA mengetahui hasil lukisan talenan peserta yang sesuai dengan target. Berdasarkan pengamatan tim mengenai pelatihan lukisan talenan ini, remaja yang berada di shelter rumah hati jombang terlihat sangat antusias sekali untuk mengikuti pelatihan ini. Remaja mantan Napi dari awal mengikuti pelatihan ini dengan sangat tertib. Meskipun mantan napi yang dianggap menjadi trouble maker, ternyata bisa membuktikan bahwa mereka juga bisa membuat lukisan talenan yang sangat kreatif dan tentunya memiliki daya jual yang tinggi.

\section{Simpulan dan saran}

Pelatihan lukisan talenan kepada remaja mantan napi di Shelter Rumah Hati Jombang dapat disimpulkan bahwa remaja mantan napi yang berada di sana sangat senang sekali atas kehadiran dari Tim PKM-M UNIPMA. Mereka sangat tertarik sekali untuk membuka usaha lukisan talenan setelah mereka keluar dari Shelter Rumah Hati Jombang, karena mereka berpikiran bahwa lukisan talenan itu memiliki daya jual yang tinggi apabila memiliki nilai estetika.

Saran untuk pelaksanaan pelatihan lukisan talenan ini adalah agar pihak shelter memberikan sarana dan prasarana membuat lukisan talenan agar mereka nantinya sudah terbiasa untuk membuat lukisan talenan setelah keluar dari Shelter dan menyediakan layanan untuk memasarkan hasil produk yang mereka buat melalui media massa (Instagram, Website dan Facebook).

\section{Daftar Rujukan}

Ardila, F., \& Herdiana, I. (2013). Penerimaan diri pada narapidana wanita. Jurnal psikologi kepribadian dan sosial, 2(1), 1-7.

Barda Nawawi Arief, 1989, Kebijaksanaan Sanksi Pidana Dalam Penanggulangan Kejahatan, Universitas Diponegoro, Semarang.

Chornik, K. (2013). Music and Torture in Chilean Detention Centers: Conversations with an Ex-Agent of Pinochet's Secret Police. the world of music, 51-65.

Darmanto, 2009, ICT dan Perempuan Usaha Kecil, Asosiasi Pendamping Perempuan Usaha Kecil

Ekasari, A., \& Susanti, N. D. (2009). Hubungan antara optimisme dan penyesuaian diri dengan stress pada narapidana kasus NAPZA di Lapas Kelas IIA Bulak Kapal Bekasi. SOUL, 2(2), 1-32.

Esteban, F., Alós, R., Jódar, P., \& Miguélez, F. (2014). 'Ex-inmates' Job Placement. A Qualitive Approach. Revista Española de Investigaciones Sociológicas, 145, 181-204.

Harsono, C. I. (1995). Sistem Baru Pembinaan Narapidana. Djambatan.

Maruna, S., \& LeBel, T. P. (2012). Revisiting ex-prisoner re-entry: A buzzword in search of a narrative. In Reform and punishment (pp. 170-192). Willan.

Muhammad Mustofa, 2007, Bantuan Hukum Untuk Terpidana Penjara (Warga Tersisih), Alumni, Bandung

Niniek Suparni, 1996, Eksistensi Pidana Denda Dalam Sistem Pidana dan Pemidanaan, Sinar Grafika, Jakarta.

Nomor, K. M. K. R. I. M. 02-PK. 04.10 Tahun 1990 tentang Pola Pembinaan Narapidana. Tahanan Menteri Kehakiman Republik Indonesia.

Pradiantiwi, D., Safitri, R. W., \& Prasasti, P. T. A. (2018). CHARACTER EDUCATION FOR PRISONERS SOFT SKILLS TO EMPOWER THROUGH ASINAN TRASI IN THE CORRECTIONAL INSTUTION NGAWI. Research Report.

Raharjo, Agus. “Mediasi Sebagai Basis Dalam Penyelesaian Perkara Pidana”. Jurnal Mimbar Hukum, Vol. 20 tahun 2008. Yogyakarta: FH UGM. 
Rifai, Edy. "Peran Hakim Dalam Penemuan Hukum dan Menciptakan Hukum Pada Era Reformasi”. Jurnal Ilmu Hukum "Preavia". Vol. 4. No.1 Tahun 2010, Lampung: Fakultas Hukum Universitas Lampung.

Shofia, F. (2009). Optimisme masa depan narapidana (Doctoral dissertation, Universitas Muhammadiyah Surakarta) 